\title{
O GRANDE MONSTRO: O ATEU NO SÉCULO XVII INGLÊS ${ }^{1}$
}

\author{
Antônio Carlos dos Santos ${ }^{2}$ \\ Universidade Federal de Sergipe (UFS) \\ https://orcid.org/0000-0002-7255-0525
}

\section{RESUMO:}

O ateu no século XVII inglês é caracterizado por uma polifonia de sentidos. Mas, como precisar o seria o ateu neste período? Qual a imagem do ateu? Qual o critério para especificar o modus operandi do ateu? Como atribuir o estatuto jurídico de alguém que é acusado de ateísmo daquele acusado de bruxaria, por exemplo? Essas são algumas questões que este texto pretende responder, tendo por objetivo mapear os vários significados de o que se entende por ateu no século XVII inglês, na tentativa de extrair um conceito.

PALAVRAS - CHAVE: Ateu; Ateísmos; Século XVII.

\section{THE GREAT MONSTER: THE ATHEIST IN THE XVII CENTURY ENGLISH}

\begin{abstract}
:
The English atheist in the 17th century is characterized by a polyphony of meanings. But, how would you say the atheist would be in this period? What is the image of the atheist? What is the criterion for specifying the atheist's modus operandi? How to attribute the legal status of someone who is accused of atheism? These are some questions that this text intends to answer, aiming at mapping the various meanings of what is meant by an atheist in the seventeenth century English, in an attempt to extract a concept.
\end{abstract}

KEYWORDS: Atheist; Atheism; XVII Century.

\footnotetext{
${ }^{1}$ Este texto faz parte de uma pesquisa maior, ainda em andamento, que conta com o apoio do CNPq.

2 Professor de Filosofia da Universidade Federal de Sergipe (UFS), Sergipe - Brasil. Pesquisador Bolsista Produtividade do CNPQ. E-mail: acsantos12@uol.com.br.
}

SANTOS, Antônio Carlos dos. O grande monstro: o ateu no século XVII inglês. Griot : Revista de Filosofia, Amargosa/Bahia, v.17, n.1, p.315-325, junho/2018. 
Há uma ideia comum sobre o que significa ser ateu entre os pesquisadores da história inglesa do século XVII: a sua imprecisão conceitual. Trata-se de uma dificuldade diante da enorme diversidade de expressões que visa a desqualificar o não crente nesse período, nos seus diferentes usos. Herege, depravado, libertino, corruptor de espírito, ímpio, perverso, fomentador dos piores crimes: esses são algumas das denominações mais correntes. $O$ ateu é entendido como um pouco de cada um desses termos. Mas, como precisar o que seria o ateu? Qual a imagem do ateu? Qual o critério para especificar o modus operandi do ateu? Como atribuir o estatuto jurídico de alguém que é acusado de ateu? Essas são algumas questões que este texto pretende responder, tendo por objetivo principal mapear os vários significados de o que se entende por ateu no século XVII inglês, na tentativa de extrair um conceito.

Em meados do século XVII inglês, o ateu é associado à imagem de um monstro (atheistical monsters), que ataca ferozmente o fundamento da religião e do Estado (MARSHALL, 1994, p. 697). Sob Crowmell, que na condição de puritano, tinha fé inabalável na Providência Divina, crescem os rumores de que o ateísmo avança em Terras inglesas. $\mathrm{O}$ medo de que castigos divinos pudessem cair sobre a Inglaterra fez com que ele ampliasse a repressão aos não crentes, razão pela qual em 1648 torna a pena de morte para quem negasse a imortalidade da alma (mortalist), refutasse a existência de Cristo, do Espírito Santo, Deus e seus poderes, além das autoridades das Escrituras, e que ficou conhecida como The Blasphemy Ordinance (SOCGARD, 2008, p. 317). Certamente, algumas destas ações são consequências da imagem do ateu como sendo perigosa e ameaçadora razão pela qual era preciso pensar uma série de medidas para conter esse avanço.

Com a Restauração, em 1660, a censura voltou a atacar alguns setores da sociedade inglesa do período. Foi na sequência deste mesmo espírito hostil a todo o sinal contrário à religião que, em 1666, o Parlamento inglês começou um procedimento jurídico contra o Leviatãa, de Hobbes. $\mathrm{O}$ curioso é que Hobbes é muito severo para com o ateu, como ele mesmo registra no Apêndice de seu Leviatã: "Aquele que nega a existência de Deus ou que a professa claramente de não saber se Deus existe ou não, mesmo que a lei não precise a pena, podemos punir, segundo a igualdade natural e enviar para o exílio. De fato, em todas as cidades, a lei ordena a religião e o reconhecimento do poder divino". (HOBBES, 1999, p. 761). No dia 31 de janeiro de 1667, uma lei contra os ateus é votada na Câmara dos Comuns e a obra do inglês é citada como exemplo de ateísmo. Ela foi acusada de levar a peste que dizimava a Inglaterra daquele momento e que no ano anterior já tinha causado enorme incêndio em Londres. O exemplo do livro era utilizado para justificar a perseguição à obra e ao autor, sob pena de novas catástrofes decaírem sob o povo inglês, caso não houvessem formas de barrar o ateísmo naquele reinado (MINTZ, 1962).

Nunca é demais lembrar que, em 1677, o Parlamento inglês fez do ateísmo uma ofensa capital e, em 1697, por meio do Blasphemy Act, condenou politeístas, falsos cristãos e quem quer que blasfemasse contra a doutrina da Trindade, reprimindo assim qualquer forma de contestação religiosa. Na verdade, desde a segunda metade do século XVII, o Parlamento inglês votou uma série de medidas religiosas para enquadrar a religião dentro dos limites da política do período, que visava 
simplesmente impor a uniformidade religiosa aos dissidentes: em 1662, a Uniformity Atc, que exige a ordenação episcopal de todo o clero e o uso obrigatório do Livro de prece comum (Book of Common Prayer); em 1664, a Converticle Act, que proibia o encontro de religiosos fora da sua paróquia; em 1665, a Five Mile Act, que bania os ministros dissidentes das cidades vinculadas à sua respectiva paróquia. Essas leis trouxeram uma série de consequências, como prisões, restrições funcionais e religiosas (WARD, 2010, p. 210; BERMAN, 1990). É neste contexto que o ateu se mostrava, assim, um perigo à vida social pelo simples fato de não demonstrar vínculo religioso nem temor a Deus, pois, afinal, como poderia haver fundamentum social sem referência a Deus?

Sob o viés jurídico, por meio da institucionalização de novas leis visando a atenuar esse perigo (é importante lembrar que, entre 1667 e 1697, foram votadas três séries de leis no Parlamento inglês, voltadas à repressão da heresia ${ }^{3}$ ), outras formas de resistência são inventadas. Uma delas fez muito sucesso, e que se estende até hoje: são as "Boyle Lectures"4. Trata-se, de fato, de sermões, sob a denominação de conferências, financiadas testamentalmente por Robert Boyle, contemporâneo e amigo de Locke. Essas conferências tinham um objetivo claro: defender a doutrina cristã com os valores da ciência contra os ateus. Elas tiveram papel fundamental não só no sentido de cumprir esse objetivo, mas de fomentar o debate sobre a relação entre a religião e a ciência nascente na Inglaterra daquele período. Elas também foram responsáveis, em larga medida, pela popularização e difusão do pensamento de Newton nas paróquias inglesas. Para que se possa entender esta polêmica, é preciso compreender o seu contexto político e religioso daquele momento inglês do século XVII.

Por volta de 1690, as lutas políticas e religiosas no interior da própria hierarquia religiosa ganhavam visibilidade, afetando o debate em torno da tolerância, incluindo aí, o ateu. A ala mais conservadora anglicana, aliada aos tories, liderava uma ofensiva contra a tolerância por meio da publicação e difusão de panfletos contra os dissidentes ou todo aquele que tivesse um perfil mais heterodoxo em relação à doutrina da Igreja na Inglaterra. O foco de toda essa empreitada era atingir os socinianos, que eram acusados de livre pensadores, deístas e ateus, e a sua expansão era interpretada por muitos como um perigo para a Inglaterra razão pela qual era importante promover várias ações para conter tal avanço. As "Boyle Lectures" nasceram nesse contexto, na tentativa de reconciliar as doutrinas cristãs com a razão, sem desconsiderar a necessidade da revelação, por um lado, e os limites da razão, por outro. Foi com esta atmosfera que em 1696, John Toland, considerado um livre pensador (freethinker) por Berkeley, publicou anonimamente, a obra Christianity not Mysterious, que atacava os mistérios cristãos e que sustentava a

\footnotetext{
${ }^{3}$ Ele é conhecido até hoje como Act for punisching and preventin Atheism, Profaneness, and profane Cursing and Swearing.

${ }^{4}$ Segundo Thomson, « Um comité de administradores foi estabelecido para nomear os conferencistas, que recebem honorários de 50 Libras por ano. As conferências aconteceram regularmente entre $1692 \mathrm{e}$ $1732 \mathrm{e}$, em seguida, de modo intermitente". Elas retornaram à regularidade algum tempo depois e, após 2004, estão sob a organização de Gresham College, na Igreja de Santa Mary Le Bow, em Cheapside. THOMSON, Ann. Les premières « Boyle Lectures » et les vérités au-dessus de la raison. In: XVII-XVIII. Revue de la société d'études anglo-américaines des XVIIe et XVIIIe siècles. 우 68 , 2011. Vérité(s) Colloque tenu en Sorbonne - 21-22 janvier 2011.p. 98.
}

SANTOS, Antônio Carlos dos. O grande monstro: o ateu no século XVII inglês. Griot : Revista de Filosofia, Amargosa/Bahia, v.17, n.1, p.315-325, junho/2018. 
estreita vinculação entre a religião e a razão, argumento este defendido pelos socinianos. O livro foi considerado um escândalo e, no início de 1700 , foi julgado e condenado pela Câmara dos Comuns (TARANTO, 2014-2015). Mas a pergunta que todo o mundo se fazia era: o que significa ser ateu no século XVII inglês?

Ser ateu era uma acusação que servia para denegrir a imagem pública de alguém que tinha o comportamento normativo contrário à ortodoxia religiosa, definida pela religião do Estado inglês. Significava também alguém ser tomado pela insensatez, pela loucura, extravagância, ou seja, pela "infidelidade sob todas as formas" (LURBE, s/ed, p.158). Nessa condição, o ateu era concebido como uma anomalia que é conduzido por uma fatalidade cega sem rumo e sem controle. $O$ pano de fundo dessa concepção é que Deus não existe porque não há a Providência, nem tampouco a imortalidade da alma com sistema de punições e recompensas. Segundo Hunter, o termo abarca dois campos sob um mesmo terreno: uma imoralidade prática e uma impiedade especulativa, desprovido de um sentido único e sistemático (HUNTER, 1985, p. 136). Essa forma de entender o ateu levou à divisão do ateu em duas categorias: o ateu de sistema, que tem caráter teórico, e o prático, que não vislumbrava uma compreensão organizada do mundo material, mas que de alguma forma contestava a estrutura religiosa existente no período. Segundo Soccard, na Inglaterra desta época, alguns não crentes negam a divindade de Cristo, outros a sua imortalidade, mas nenhum ousava negar a existência de Deus (SOCCARD, 2008, p. 314). Ou seja, neste momento, contestava-se quase tudo, menos a figura divina.

Robert Boyle, no texto intitulado Discourse of Things above Reason, de 1681, faz a distinção entre as verdades reveladas contra e a favor da razão. Aquelas abaixo da razão, segundo ele, são as verdadeiras porque não se pode demonstrar pela razão. Em suas palavras, "as coisas para além da razão, livre da escuridão e da ambiguidade, não devem ser concebidas e compreendidas pela nossa faculdade racional" (BOYLE, 1991, p. 210).

John Locke, no Ensaio sobre o entendimento humano, apresenta o mesmo problema de Boyle, mas fornece uma outra solução, bem mais ousada do que seu amigo. Se o químico pensa que Deus só pode existir para além da razão, que passa pelos mistérios da revelação, o filósofo sustenta que Deus é demonstrável racionalmente. Registra ele em três pontos fundamentais: "a) São conforme a razão as proposições cuja verdade pode ser descoberta examinando e seguindo os traços, as ideias que recebemos da sensação e da reflexão e que se pode achar verdades ou prováveis pela dedução natural. b) São acima da razão as proposições cuja verdade e a probabilidade não pode ser derivada pela razão desses princípios. c) São contrárias à razão as proposições que são em contradição com nossas ideias claras e distintas, ou irreconciliáveis com elas. Assim, a existência de um DEUS é conforme a razão, a existência de mais de um DEUS contraria à razão; a ressurreição dos mortos é acima da razão". E continua Locke com o mesmo tema: "Resumindo, mesmo que acima da razão possa ser entendido num sentido duplo (significando seja acima da probabilidade, seja além da certeza), e também contrário à razão pode por vezes ser tomado, eu suponho, em sentido largo do termo" (LOCKE, Essay, IV,17, 23).

Apesar desse viés racional, Locke não abre mão da fé, muito menos do aspecto moral que toda a religião prega. Foi neste contexto que entre 1697 e 1699 houve um caloroso debate envolvendo o bispo de Worcester, defensor da Trindade, que criticou

SANTOS, Antônio Carlos dos. O grande monstro: o ateu no século XVII inglês. Griot : Revista de Filosofia, Amargosa/Bahia, v.17, n.1, p.315-325, junho/2018. 
Locke e o associou às ideias de Toland. Na prática, Locke foi acusado de subverter a moral, de ser partidário da religião natural e, o que é mais grave, de pertencer ao socinianismo, que é um modo de entender o cristianismo, mas sem a imortalidade natural da alma e o dogma da Trindade. Locke o respondeu e justificou que seu pensamento considera sim os aspectos da revelação cristã e acusa o bispo de encorajar o deísmo e a irreligião por exigir uma demonstração racional da imortalidade da alma ${ }^{5}$.

Embora o bispo tenha morrido em meio a esta discussão, a polêmica continuou envolvendo outros pensadores da época, como Pierre Bayle. No seu Dictionnaire Philosophique, verbete "Dicéarque", retomou os argumentos essenciais da controvérsia, dando razão a Locke. Afirma ele: "O Senhor Locke se apoia sobre as Escrituras na persuasão da imortalidade da alma, ele tem tanto de ortodoxo cristão quando de evangélico e teológico, que se pode ter. $O$ que ele disse sobre esta questão é admirável". Vemos, então, que a contenda ganhou proporções gigantescas, cujo centro era evitar a propagação do ateísmo.

Enfim, as "Boyle Lectures" foram importantes seja como foco do debate em torno do papel da razão em relação à religião, seja o da revelação em relação aos mistérios da Trindade e da Ressureição. Aqui se encontrava o coração de toda a polêmica: a necessidade da defesa de uma posição teológica racional diante dos perigos dos entusiastas fanáticos, por um lado, mas havia a necessidade de responder ao racionalismo que esvaziava a religião de toda a sua substância, representado na figura ora do ateu, ora do siciniano, por outro lado. A saída, portanto, era conciliar as verdades da religião com as da ciência, guardando, de modo especial, os seus mistérios.

É importante destacar que a luta contra o ateísmo não é só moral, é também teológica, porque se exige uma explicação racional da existência de Deus e sua ação no mundo a fim de que os homens pudessem melhorar enquanto cristãos. Como afirma Thomson, "as conferências recorriam a argumentos diferentes, mas complementares: para reconciliar a religião à ciência (...) demonstravam a existência racional de Deus e da alma imaterial; mas para defender os mistérios, sublinhavam as Escrituras e a Revelação de um lado e os limites da razão humana por outro" (THOMSON, 2011, p. 110).Vemos, assim, que se a sociedade não admite o ateu, seja por contestar a importância de Deus no mundo, seja por ser uma depravação moral, isso nos leva à conclusão aparentemente simples: a religião no século XVII inglês era uma questão pública daquela sociedade. Ela ainda não tinha se tornado um objeto de foro privado, e por isso a sua importância política e social.

Se a religião é uma atividade do indivíduo na esfera pública, como interpretar o ateu no século XVII inglês? Há, grosso modo, cinco escolas interpretativas diferentes, ao menos segundo Daled: a) aquela que defende que o ateísmo existe, apesar de tudo (Busson, é, talvez, o mais conhecido); b) aquela que defende que a ideia segundo a qual o ateísmo seria um mito da Renascença (Kristeller, seu notável líder); c) aquela que sustenta que o ateísmo não existe (Kors é um de seus maiores

\footnotetext{
${ }^{5}$ Locke introduz a hipótese da thinking matter no livro IV do Ensaio sobre o entendimento humano, capítulo III, 6. Contudo, o que vai dar visibilidade ao tema será o debate travado entre Locke e o Bispo de Worcester, entre 1696 e 1697. Todos os textos de Locke sobre esta discussão da matéria pensante estão em LOCKE, J. In: Works, T. IV.
}

SANTOS, Antônio Carlos dos. O grande monstro: o ateu no século XVII inglês. Griot : Revista de Filosofia, Amargosa/Bahia, v.17, n.1, p.315-325, junho/2018. 
expoentes); d) aquela que defende que o ateísmo existe, mas é mascarado (Mori é um dos defensores mais conhecidos); e) aquela que se pauta no ateísmo vinculado às "luzes radicais" (Israel é o grande intérprete dessa corrente). Ou seja, há uma gama de teorias, bem distintas entre si, e que aponta para um ateísmo que flerta com o materialismo e por isso apresenta um discurso ambivalente e por vezes dissimulado. Ou seja, há uma série de autores na era moderna que apresentam princípios materialistas e fortes dilemas éticos religiosos de difícil precisão ou definição (DALED, 2013, p.45-61).

O termo ateu tem origem no grego e foi traduzido pelo latim e línguas vernáculas europeias para estigmatizar aqueles que, por palavras ou atos, negavam a existência de Deus. Kors, especialista sobre o ateísmo na idade moderna, registra que nesta época ninguém se auto intitulava ateu, primeiro porque não havia uma doutrina sistemática que o sustentasse enquanto fundamento, e em segundo lugar, porque dada à falta de definição, qualquer um era acusado de ateu, razão pela qual ele nomeia um capítulo de seu livro como "ateísmo sem ateu" (Atheists without atheism). Neste contexto, o ateu passa a ter uma conotação de injúria, de infâmia, de acusação e denunciação. Devido ao seu uso de caráter violento, o ateu não deve ter lugar na sociedade razão pela qual, não raras vezes, foi condenado à morte, dada à sua figura absolutamente indefensável, seja pela perversidade moral, seja pela mental (KORS, 1990). Declarar-se ateu era o mesmo que assinar um atestado de morte (CAVAILLÉ, 2013, p. 16). Por esta razão, o eventual ateu ao publicar uma obra, usava diversos métodos de dissimulação, como pseudônimos, publicação póstumas, ou de forma clandestina sem o nome do autor porque havia uma espécie de criminalização da figura do ateu.

Todavia, apesar deste cenário, o ateu jamais deixou de existir e ter, ainda que de forma restrita, redes de sociabilidade, como as sociedades filosóficas, acadêmicas, os salões, as lojas maçônicas, ainda que secretas ou clandestinas. Por meio desta rede complexa de ideias, passavam subversivos sistemas filosóficos e científicos inovadores. Com tantos qualificativos negativos, não era fácil detectar um ateu autêntico e por isso Staquet defende a ideia de que nas portas da era moderna havia dois tipos de ateísmo: um velado e outro explícito, embora a distinção entre ambos seja menos radical e nuançada. Isto se deu porque os autores foram obrigados a esconder sua concepção religiosa e criaram verdadeiros códigos de leituras com estratégias de dissimulação e filtro a fim de não ser censurado ou de camuflar o seu pensamento para o leitor ávido por conhecimento (STAQUET, 2013, p.10).

Popkin, talvez, é quem melhor traduz o quadro desse conceito: "O termo 'ateu' no final do século XVI e início do século XVII era usado com um sentido pejorativo, e não descreve de fato a posição de ninguém, se 'ateu' for entendido como aquele que nega a existência de Deus e a visão judaico-cristã da natureza e do destino humanos. Pensadores críticos tinham interpretações diversas e dúvidas sobre aspectos da verdade da posição religiosa. Mas o ateísmo como negação da existência de um Deus atuante na história e como uma negação do relato bíblico enquanto retrato verdadeiro de como a história teve o seu início e progrediu, é uma visão típica de meados do século XVII que se desenvolveu com base nas heresias de La Peyère e no seu ceticismo aplicado ao material religioso" (POPKIN, 2000, p. 332). Para além

SANTOS, Antônio Carlos dos. O grande monstro: o ateu no século XVII inglês. Griot : Revista de Filosofia, Amargosa/Bahia, v.17, n.1, p.315-325, junho/2018. 
da imprecisão conceitual, há em todas essas figuras, a objeção moral radical e que apresenta conotação altamente negativa do ponto de vista social.

O termo ateu, por um lado, ganhou um sentido stricto sensu, mas com uma conotação metafísica, para traduzir o sentido largo da palavra descrença (unbelief), e há, por outro lado, uma outra definição, mais com teor filosófico, que significa aquele que está persuadido de que Deus não existe. De qualquer modo, essas duas acepções têm um traço comum: o ateísmo seria uma prática rebelde e indisciplinada, "sinônimo de imoralidade, de perversão, de dissolução" (MORI,1999, p.189). Por esta razão, havia sempre a vinculação do ateu com o libertino, o herege ou um monstro profano, que tem um instinto obscuro, fundado na ignorância. Como diz Minois, foram os libertinos que plantaram os "germes do ateísmo".

Neste sentido, o conceito de ateu surge das entranhas religiosas. Não custa lembrar que o século XVII foi o tempo em que os grandes sistemas filosóficos e teológicos se encontraram e ao mesmo tempo se combateram. Foi nele também que a ordem social, política e religiosa foram questionadas e radicalizadas e a face mais bem acabada dessa ordem está na figura do libertino, no contexto do teológicopolítico. Ou seja, no momento em que a Reforma e a Contra-Reforma protestante mudaram radicalmente a relação entre o homem e a divindade, ainda no século XVII, construiu, assim, o seu fundamento: Deus governa o mundo tal qual um Imperator romano, mas também Ele se relaciona com o homem por meio da Graça. Esta mediação é a chave do humanismo da Renascença. Mas não basta a vontade divina sobre o homem, é preciso entender a vontade do homem para com Deus. Ora, é com esta perspectiva que surgem os libertinos que vão contestar seja a ordem religiosa seja a nova visão do mundo (LURBE, 2014).

O libertino se confunde ora com o deísta, ora com o ateu, com o panteísta, ou mesmo com o livre pensador. Nascido das entranhas do espírito apologeta, o libertino foi um inquieto que questiona a existência de Deus, sua Providência e Sua ação entre os homens através de uma subversão intelectual e moral. Ele foi interpretado, no fundo, como um ateu, que, por diferentes perspectivas, agia sob a forma da heresia, da impiedade, da contestação, da crítica, da agitação. $O$ fato é que não importavam os meios, o libertino sempre se opôs à religião, razão pela qual bastava ser denunciado como crítico da religião estabelecida para ser acusado e por isso o termo foi uma arma polêmica. Ele foi direcionado com a mesma violência para atingir sejam os cristãos sejam os socinianos, críticos católicos ou mesmo protestantes, como se todos fizessem parte da mesma comunidade, a de críticos da religião de forma homogenia e uniforme, sem nuances.

Num sentido mais raso do termo, o libertino significava a liberação da tutela religiosa, seja da parte da religião institucional, seja dos costumes socialmente aceitos como regras de vida. Ora, o libertino, na impossibilidade de viver fora das normas, admitia as leis da natureza como fundamento básico do viver, razão pela qual se pautava por uma liberdade natural, uma religião natural ou uma moral natural. Negligenciando os adereços de uma vida social intensa, preferia os pequenos grupos, o que trazia como consequência, a ausência de uma concepção política mais bem-acabada. Não tinha tampouco projeto de difusão de suas ideias junto ao povo, razão pela qual o ateísmo seria o fundamento filosófico dos libertinos já que ele: 1) nega a existência dos deuses; 2) a criação do mundo e a imortalidade da alma; 3) a 
existência dos infernos, dos paraísos, dos anjos e demônios; 4) defende uma moral natural; 5) reivindica o direito natural do indivíduo.

Ora, o ateu, longe de ser imoral, ele segue o fundamento mesmo do Evangelho, ou seja, a ideia segundo a qual "não podemos fazer com o outro o que não queremos que se faça conosco mesmo", por um lado, e o "amor de si" enquanto expressão de um princípio de conservação natural, por outro. Como afirma Gengoux, o libertino é o tipo de homem cujas "ideias encontram maior coerência no ateísmo, seja ele declarado ou não" (GENGOUX, 2016, p. 14). Ou seja, o ateísmo seria a face teórica de um modo libertino de ser prático. Isto significa dizer que o ateísmo, sobretudo de face libertina, é uma posição filosófica diante do mundo. Isto quer dizer que era muito difícil encontrar um tipo de ateu "puro". Ele quase sempre era associado a outras figuras igualmente não tão nobres como o ateu.

Mas esta vinculação entre ateísmo e o lastro religioso encarnado no libertino não é algo exclusivo nem tampouco consensual entre os pesquisadores da área. Isso porque, como já foi dito acima, o termo se prestava a todo de significação, razão pela qual não poderia ser considerado apenas um problema religioso ou filosófico. Segundo Cavaillé, o termo ganhou muito espaço no século XVII e se manifestou na vida das pessoas de diferentes formas, captado pela filosofia: "nas manifestações de dúvidas e de crença, às vezes subterrâneas e difusas, de rebeliões sociais contra o clero, o poder político e econômico, mas também ético, que a filosofia deu uma forma teórica" (CAVILLÉ, 2007, p. 2). Isto significa dizer também que o conceito de ateu é tão amplo quanto impreciso e que só ganhou maior precisão no final do século XVII, significando "a crença de que Deus não existe" (KORS,1990, p. 44), razão pela qual não pode ser tolerado. Esta imprecisão também era vista na Inglaterra e certamente Locke tinha clareza dela. Segundo Marshall, "os ateus eram assim claramente considerados intoleráveis. E, em parte, pelo processo de assimilação dos ateus, os hereges anti-trinitarianos foram considerados quase igualmente intoleráveis aos olhos de muitos pensadores do século dezesseis e início do século XVII" (MARSHALL, 2006, p. 262). O ateu é intolerável porque não crendo em Deus, não acredita nas normas, tampouco nos pactos sociais e por isso, todo o fundamento social fica ameaçado, tal qual defende Locke no final da Carta sobre a tolerância.

Se no Grande Século ainda não há o conceito de ateu, e se qualquer dúvida sobre a Providência, as Escrituras, os Santos, passava a ser interpretado como "monstruosidade intelectual", como definir o ateu? Em virtude dessa polifonia do que se entende por ateu, há certos comentadores que se recusam a pensar o ateísmo no século XVII. Lucien Fèbvre, por exemplo, afirma que se trata de um anacronismo pensar o ateísmo na idade clássica, razão pela qual prefere usar o termo da descrença (FÈBVRE, 1947). Essa estratégia significa dizer que o ateu passa a ser definido por aproximação, ou seja, por aquilo que ele representa: um crítico voraz das instituições e dos homens, mas sem negar a existência de Deus.

Segundo Paul Hazard, o crítico da religião atinge todas as instituições, mas não atinge a figura de Deus. Ele dá o exemplo de deísta, que é a porta de entrada para o ateísmo. Ainda segundo esse comentador, o objeto da crença do deísta é impreciso porque a religião revelada constitui uma condição suficiente, mas não necessária. O deísta admite a crença em Deus e o seu culto público, mas Ele não se imiscui nas questões humanas; a Providência existe, mas não há crença na 
imortalidade da alma ou a vida após a morte; enfim, segundo suas palavras, "um deísta é um homem que ainda não teve tempo de tornar-se ateu" (HAZARD, 1961, p. 241) e por isso é muito mais fácil ser deísta do que romper com toda a estrutura religiosa de forma brutal, como pode acontecer com o ateu.

É importante entender que o termo deísmo teve origem na Itália do século XVI, pelos socinianos, justamente para se distinguirem dos ateus. Ele porta uma sutil nuance, mas pejorativa, porque denota quase sempre uma reprovação do olhar ortodoxo, em relação aos que creem em Deus, mas sem aceitar os dogmas ou as práticas ritualísticas de uma determinada religião, bem como uma autoridade religiosa. Isto quer dizer que o deísta rejeita Deus da revelação, mas admite a existência de um Ser Supremo, fundado nas faculdades naturais da razão humana (FOULQUIÉ,1962, p. 157).

No fundo, o termo está entre o cristianismo e a sua negação razão pela qual ele serve a todo o tipo de interpretação duvidosa. O deísta vê o mundo como uma máquina que funciona por si mesmo, autorregulada, sem necessidade de um criador. Embora o deísta creia em um Ser Supremo, sua existência e natureza podem ser conhecidas pelas faculdades naturais humanas. Esta concepção de deus passou a ser conhecida historicamente como "Deus dos filósofos" em oposição ao "Deus das Escrituras" ou fazendo parte do léxico da "religião natural" em contraposição à "religião positiva" da ortodoxia cristã. Assim, o deísmo é uma espécie de antessala do ateísmo, sendo que os dois, como registra Pascal, são abomináveis: "todos os que procuram Deus fora de Jesus Cristo (...) caem ou no ateísmo ou no deísmo, que são duas coisas que a religião cristã abomina quase igualmente" (PASCAL, 2000, p.581).

Enfim, quando Locke expulsa os ateus de seu sistema da tolerância tem em mente justamente essa figura execrável, que é o ateu, sem um sentido propriamente conceitual, tendo clareza de que ele não cumpre os pactos sociais e isso seria razão suficiente para que não convivesse com os demais. Ora, qual figura que encarnaria esse alto grau de perversão se pudéssemos comparar com o ateu do século XVII? Para Cavaillé, a imagem do pedófilo no mundo contemporâneo corresponderia à figura abominável do ateu no Grande Século. Em suas palavras, "deixemos os pedófilos nas mãos dos psiquiatras com o mesmo desgosto e a mesma angústia que se remetia o ateu presumido nas mãos do Estado" (CAVAILLÉ, 2013, p. 20). Ou seja, a melhor representação dessa figura é o próprio monstro, como uma hydra de duas cabeças que tem dois objetivos comuns: atacar o fundamento do Estado e da religião, por um lado, e que mina toda a sociabilidade possível por meio da moral, por outro. $O$ ateu, nessas condições, contesta a divindade e suas qualidades, ao mesmo tempo que põe em perigo a sociabilidade. De fato, não dá para conviver com essa criatura, tão estranha quanto perigosa. 


\section{Referências bibliográficas}

BERMAN, D. A History of Atheism in Britain : From Hobbes to Russell. London and New York : New Fetter Lane and Routledge, 1990.

BOYLE, Robert. Selected Philosophical Papers. Ed M. A. Stewart. Indianapolis : Hackett, 1991.

BUSSON, H. Les noms des incrédules au XVI siècle. In Bibliotèque d'humanisme et renaissance. Genève, Droz, t. XVI, 1954.

CAVILLÉ, Jean-Pierre. Libertinage, irréligion, incroyance, athéisme dans l'Europe de la première modernité (xvie-xviie siècles). Une approche critique des tendances actuelles de la recherche (1998-2002). Les Dossiers du Grihl [En ligne], 2007.

DALED, P. Rhétorique masquée et ambivalence dans l'historiographie de l'athéisme. In: STAQUET, A. Atheísme voilé aux temps modernes. Académie royale de Belgique, Bruxelas, 2013, p.45-61.

FÈBVRE, L. L'incroyance au XVIe siècle. La religion de Rabelais. Paris, Albin Michel, 1942, 2 ed. 1947.

FOULQUIÉ, P. Dictionnaire de la langue philosophique. Paris : PUF, 1962.

GENGOUX, N. "Rôle de l'athéisme dans la pensée libertine : quelles Lumières ? ", ThéoRèmes [En ligne], 9 | 2016.

HAZARD, P. La crise de la conscience européene. Paris : Payard, 1961.

HOBBES, T. Leviathan. Paris, Dalloz, 1999.

HUNTER, Michael. The Problem of 'Atheism' in Early Modern England.

Transactions of the Royal Historical Society, Vol. 35 (1985).

ISRAEL, J. Radical Enlightenment : Philosophy and the Making of Modernity 1650-1750. Oxford : Oxford University Press, 2001.

KORS, A. Atheism in France 1650-1729: The orthodox sources of Disbelief. Princeton, Princeton Unicersity Press, 1990.

LOCKE, John. The Works of John Locke in Nine Volumes. London: Rivington, 1824, 12 th ed.

LURBE, Pierre, et Sylvie TAUSSIG, eds. La Question de l'athéisme au dix-septième siècle. Turnhout : Brepols, 20042.

MARSHALL, John. John Locke, Toleration and Early Enlightenment Culture. Cambridge : Cambridge UP, 1994.

MARSHALL, J. John Locke, toleration and early enlightenment culture. Cambridge, Cambridge University Press, 2006.

MINOIS, G. 1998. Histoire de l'athéisme. Paris, Fayard, 1998.

MINTZ, S. I. The Hunting of Leviathan. Cambridge, University Press, 1962.

MORI, G. Bayle philosophe. Paris, Honoré Champion, 1999.

PASCAL, B. Pensées. Paris: Livre de poche. 2000.

POPKIN, R. História do ceticismo de Erasmo a Spinoza. Rio de Janeiro, Francisco Alves, 2000.

SOCGARD, S. L'exclusion des athées par Locke. L'envers théorique d'une convention politique. In: XVII-XVIII. Revue de la société d'études anglo-américaines des XVIIe et XVIIIe siècles. $\mathrm{N}^{\circ} 65,2008$.

STAQUET, A. Atheísme voilé aux temps modernes. Académie royale de Belgique, Bruxelas, 2013.

SANTOS, Antônio Carlos dos. O grande monstro: o ateu no século XVII inglês. Griot : Revista de Filosofia, Amargosa/Bahia, v.17, n.1, p.315-325, junho/2018. 
TARANTO, P. Philosophie des Lumières et secularisation. Université de Paris I, Sorbonne, 2014-2015.

THOMSON, Ann. Les premières «Boyle Lectures » et les vérités au-dessus de la raison. In: XVII-XVIII. Revue de la société d'études anglo-américaines des XVIIe et XVIIIe siècles. $N^{\circ} 68,2011$. Vérité(s) Colloque tenu en Sorbonne - 21-22 janvier 2011.

WARD, Lee. John Locke and modern life. New York : Cambridge University Press, 2010 .

Autor(a) para correspondência: Antônio Carlos dos Santos, Universidade Federal de Sergipe, Departamento de Filosofia, Av. Marechal Rondon, S/N, Rosa Elze, CEP 49100-000, São Cristóvão SE, Brasil. acsantos12@uol.com.br 